\title{
Research and Practice for Design and Making of Microlecture
}

\author{
Liang Chang \\ School of Computer Science and Technology \\ Xi'An University of Science and Technology \\ Xi'An, China \\ changl@xust.edu.cn
}

\author{
Shangfu Gong \\ School of Computer Science and Technology \\ Xi'An University of Science and Technology \\ Xi'An, China \\ gongsf@xust.edu.cn
}

\begin{abstract}
Modern information technology used in teaching brings tremendous changes to teaching mode and effects. Appearance and application of microlecture make learners not be restricted to space and time. It has formed a new learning resources organization method for ubiquitous learning environment and informal learning. The paper combined with teaching experiences expounds method of design and making microlecture from several aspects of recognize and understanding, types, features, design and making of microlecture, and its impellent functions to construct open sharing resources for school, aiming at discussing together and sharing with education.
\end{abstract}

Keywords-microlecture; design and making of microlecture; open learning; construct sharing resources

\section{INTRODUCTION}

To thoroughly understand and implement the spirit of "developing project of education informatization for ten years from 2011 to 2020" of national education ministry, train college students to develop abilities and methods of active learning and self-study, integrate modern information technology and teaching process in depth and adapt to requirements of cultivate applied talents, design and making of microlecture have gradually risen in the field of education in recent years, also universities have launched design and making of microlecture and organized competition and evaluation in different degrees ${ }^{[1]}$. Combined with own teaching experiences and understanding to microlecture, this paper put forward a new learning resources organization method named ideas and methods of microlecture resources construction, that suitable for ubiquitous learning environment and informal learning of teachers and students, that is the key of how to design and make microlecture is to discuss and share with teachers.

\section{KNOW AND UNDERSTAND FOR MICROLECTURE}

Microlecture is a kind of video files for online teaching and learning on the internet. It is mainly used for teachers' training and students' autonomous learning. Microlecture mainly aims at centering on certain knowledge including key point, difficult point and doubtful point, or teaching links during educating and teaching process of teachers inside and outside the classroom. Its contents directly point to specific problems and pay attention to "small phenomena, small stories, small strategies and so on". One lesson explains one thing in gradually expanding way with depths and interests that can inspire students to think deeply. Microlecture resources can effectively solve problems and confusions of classroom teaching reform, promote professional development of teachers, strengthen construction of open sharing resources, further improve teaching reform, and deepen construction of efficient classroom and extracurricular learning.

Microlecture is based on the idea of teaching design. It is a video with audio in 5 to 15 minutes using multimedia technology to center on explaining certain knowledge points. These points can be not only interpretation of textbook, careful explanation of question types and summary of test centers, but also knowledge interpretation and showing in the aspect of skills as passing on methods and teaching experiences.

The difference between microlecture and class teaching is that microlecture is not used for class teaching in real time. Microlecture is an embodiment of simulating one-to-one interpreting situation distinguishing from one-to-many teachers' class teaching situation. Microlecture that similar to one-to-one teaching lays stress on students' autonomous learning and explains one knowledge point in a short time. It should avoid moving blackboard, but solve key problems that conventional teaching has difficulties with.

Moreover, the system of conventional video course is complete, its contents are detailed and complicated, its processes are tediously long, its resources are changeless and difficult to modify, also it has character of being based on teachers' teaching and guiding. The difference between microlecture and conventional video courseware is that microlecture has its own advantages, such as small capacity, highlighted theme, single content, easy to search, easy to spread, wide application range, flexible to use. At the same time, the recording and learning objects of microlecture can be anyone.

The central constitution of microlecture is classroom teaching video ((lesson fragment). It also contains assistant teaching resources related to teaching theme, such as teaching design, courseware material, teaching profound consideration, practices and tests, students' feedback, teachers' comments and so on. These contents together build a semi-structured and thematic "small environment" of resource unit application by a certain organization relationship and presenting mode. 
Therefore, microlecture not only has many kinds of teaching resources that different from conventional resource with single type, like teaching lesson, teaching courseware, teaching design and reflection, but also becomes a new type of teaching resource that inherits and develops on the basis of conventional resource.

The function of microlecture is to uncover doubts not to teach only. So it can be used for online teaching after school without time and space limitation, but it cannot replace classroom teaching for new knowledge. This mainly reflects in two aspects: (1)Microlecture is a carrier that records experiences and methods of excellent teachers. Many developed microlecture courses can directly provide study to teachers and students as it directly solves small problems around them. Teachers and students are very concerned about these problems and willing to look and to learn; (2) Microlecture is a way of research that guides ordinary teachers and students to carry out their own personalized study suitable for them, so as to change patterns and ideas of education, teaching and research.

\section{TYPES OF MICROLECTURE}

In foreign countries, the earliest concept of microlecture is put forward by David Penrose who is a senior teaching designer and an online college service manager from San Juan college of New Mexico in America in the autumn of 2008. In China, experts and scholars with the lead of Fan Guoyu who is a founder of microlecture have formally researched developing technology of enterprises' microlecture. Li Yuping and others have introduced and applied development and making of microlecture into education and teaching process at school $^{[2][3]}$. At present, the form of making microlecture is mainly divided into three types:

The first type: PPT microlecture. This course is relatively simple. PPT consists of texts, musics and pictures. Design function of autoplay for PPT, and convert into video with about 5 minutes.

The second type: Lecture microlecture. According to requirements of microlecture, instructors make shoot for teaching in accordance with modularity, and then make edit conversion to form microlecture with 5 to 10 minutes.

The third type: Scene play microlecture. This course draws lessons from shooting mode of Hollywood blockbuster. Enterprises organize research and development team to make a scene play for contents of microlecture. This team needs to design, plan, write scripts and choose directors, actors and sites to shoot. Though producers edit and make video at a later stage, this video ultimately becomes microlecture with 5 to 10 minutes.

\section{CHARACTERISTICS OF MICROLECTURE}

Microlecture teaches only one or two points of knowledge without complicated system of courses, numerous teaching targets and numerous teaching objects. It seemingly has no systematic and comprehensive properties, so that many people call it "fragmentation". However, microlecture aims at specific target groups and transferring specific knowledge.
One microlecture itself is still in need of systematic property; a set of microlecture expressing knowledge still need comprehensive property. Thus, microlecture should have the following characteristics:

1) Oral instruction. Lectures can appear on camera, can do voiceover, must instruct with colloquialism. At the same time, lectures should make courses appeal to students and make students easy to understand.

2) Streaming media player. It can be broadcasted by streaming media player based on internet, such as video, animation and so on.

3) Shorter teaching time. In general, the time for 5 to 15 minutes is appropriate. The time should be at least 1-2 minutes. The longest time is not suitable for more than 20 minutes.

4) Less teaching contents. Highlight knowledge points or skill points of one subject. A lesson of microlecture only explains a particular knowledge point. If this knowledge point contains another one, the other lesson of microlecture needs to be made.

5) Smaller resource capacity. Smaller capacity can achieve easy to play for adapting to learning with mobile devices.

6) Exquisite teaching design. Complete, careful design of informationize teaching achieves its own understanding on existing knowledge and textbooks' expressed knowledge, but not directly lists textbooks' knowledge. Otherwise, microlecture will not have functions of unraveling doubts and giving guidance in study or training.

7) Classic topics demonstration. Explaining real, specific, typical knowledge points (key and difficult points) and exercise problems (real topics and practice tests) should not be tedious according to textbooks.

8) Based on autonomous learning. Courses provided to students for autonomous learning is one-to-one guidance learning.

9) Simple and practical making. To make microlecture with varieties of methods and equipments is for practical purposes.

10) Matching related materials. Microlecture needs to match related exercises, resources and evaluating methods.

\section{MICROLECTURE IMPROVES DEVELOPMENT AND APPLICATION OF SCHOOL TEACHING RESOURCES}

\section{A. Plan contents of microlecture}

Universities must firstly make an integral program for construction contents of microlecture, determine construction plan and process and form construction standards and system to avoid duplication and disorderly development. Content program is an important work that in accordance with curriculum standards and open resources construction requirements of school, organize subject experts and teachers in teaching first-line to jointly determine knowledge field and knowledge points system of various professional disciplines, then publish together after soliciting opinions for schools' and teachers' choosing and developing. 


\section{B. Construction of resource platform}

Microlecture platform is the basis for construction and application of open share information resources in school. School should pay more attention and make a plan to guide publishing together. The function of information resources platform is to add functional modules like users' development, submission, application and research on the basis of meeting daily construction and management of microlecture resources and to form "one-stop" service environment for construction, management, application and research of microlecture.

\section{Design and development of microlecture}

Design and development of microlecture contents is more complicated system engineering. The building pattern of microlecture generally has collecting assessment type for the teachers and project development type for schools and organizations. Microlecture resources construction generally ensures quality of resources through propaganda, technical training, topic design, lesson shooting, post processing, online reporting, auditing and issuing, and evaluation and feedback.

\section{Exchange and application}

Exchange and application are ultimate goals of microlecture construction. Through focusing on broadcasting, expert comments and sharing exchange, microlecture recommends and displays outstanding award works to majority of teachers and students; regularly organize teachers to carry out observation, learning, reviewing course, reflection, discussion of microlecture library and other activities, promoting school research and new pattern of local area network teaching based on microlecture.

\section{MAKING PROCESS OF MICROLECTURE}

\section{A. Elements of Making Microlecture}

Key elements of design and making microlecture are (1) selected topics; (2) write teaching plan; (3)making courseware; (4)implementation and shooting of teaching; (5)later editing and on-line application.

Selected topic of microlecture is the key part of making microlecture. A good topic is important to success. Topics must be teaching emphases and difficulties. One course of microlecture typically teaches one knowledge point. The choice of this knowledge point is related to design of knowledge structure. Utilizing important and difficult points in teaching to make microlecture is a better selection. It can be beneficial to share teaching resources, remove doubts from students and teachers, and inspire study. Moreover, selected topic should be appropriate for multimedia characteristic in order to reflect its interests and visuality, so that increasing learning desire of viewers. Thus selected topics of microlecture should be suitable for multimedia expression, then need to add abundant graphs and images, colorful flash and videos with sound.

Secondly, teaching design and teaching plan should be written carefully. Although microlecture has only a few minutes, it needs to do a good teaching design. Good microlecture should be orderly and can effectively solve practical problems of teaching. It also should remove doubts and mobilize initiative of learners.

Thirdly, the design of PPT is an important link of microlecture. It is not only to broadcast contents, and also to attract learning interests. The following aspects should be extremely noticed:

1) Advertent problems of content design

PPT includes central contents. Unimportant contents can be expressed by teacher's mouth and motion. Design of PPT contents need to have instructive property. It also should have suspense and think about contents distribution and arrangement.

2) Advertent problems of layout design

Design of microlectures' home page and front cover had better use home page of PPT as front $\operatorname{cover}^{[5]}$. In this way, knowledge points and authors can be known absolutely clear. The layout of front cover can be visually compared to human face $^{[6]}$. "Forehead": if microlecture is a series, here we can explain series course' name and also can place unit logo; "eyes": can place simple microlecture title; "nose": place names of authors and companies; "mouth": place professional disciplines, chapters and names of textbooks; "ears": can set up edge materials to increase beauty. Background design: like human skin, gives first place to materials as far as possible with foiling texts. It should not too bright, otherwise visually appears opposite effects.

Design of middle page should reflects that knowledge small title can be written on the top line for making clear. Subject contents can be placed in the middle. Lower right corner or lower left corner should leave a blank in order to place teacher image, also not to block texts. Background should be simpler than home page, but is not recommended no background or solid color background. Too fade image can reduce visual impact. End page design: can add some language like gratefulness, microlecture topics, welcome to watch other microlecture. This page is not proposed to add teachers' image.

3)Advertent problems of aesthetic design

Local suggestions of the whole PPT: layout effects should be that texts occupy $50 \%$, pictures occupy $20 \%$, blank occupy $30 \%$. Texts should not exceed 3 kinds of colors in PPT. It is best to use only two kinds of colors to distinguish title and text Pages should be unanimous and harmonious. The contents of upper half page and next half page need to balance for avoid phenomenon of imbalance. Page turning of flash and movement can have several kinds of methods in order to attract viewers' attention. But it should not be too garish. Page turning had better choose 2-4 kinds of modes. Do not appear successive pages that have all pictures or all texts for avert aesthetic fatigue.

\section{B. Recording and Editing}

\section{1)Important points of recording}

- Background of microlecture recording need to be simple, preferably white or light color without appearing other sundries. 
- Size of sound should be reasonable. Camera angle had better from the front without being hazy.

- If not accustomed, it can let a student sit in the opposite. It's like that giving tutorial to him.

- Don't make recording as PPT effects of classroom teaching.

- When recording, adjust computer resolution ratio as $1024 * 768$ and color bits as 16 .

2) Making principle in later stage

- Time should be controlled in about 5 to 15 minutes. If more than 15 minutes, it need to compress as far as possible.

- If sound is too small or too large, it should be adjusted properly.

- The size of video is: $640 * 480$ or $320 * 240$. The format of video is FLV and MP4. The audio is best to use MP3 format.

\section{Several methods of making microlecture}

\section{1). Use external video tools to shoot}

a) Tools and software: to use teaching demonstrate tools, such as portable video, blackboard and chalk;

b) Making method: shoot recording of teaching process;

c) Process description: at first, aiming at microlecture topics, do detailed teaching design to form teaching plan. Secondly, use blackboard or projection to develop teaching process and utilize portable video to shoot the whole process. Thirdly, do a simple making for video in later stage, and make necessary edit and beautification.

2).Computer screen recording software $+\mathrm{PPT}$ file

a)Tools and software: computer, headset with microphone, video recording software like Camtasia studio, snagit or CyberLink Youcam, and PPT software ${ }^{[4]}$.

b) Making method: make screen recording for PPT demo file, supplemented by sound recording and subtitles.

c) Process description: firstly, aiming at selected teaching subjects, collect teaching materials and media materials to make PPT courseware. Secondly, while open video recording software and teaching PPT on the computer screen, instructors with headset need adjust position and volume of microphone, then adjust PPT interface and location of screen interface. After these, instructors click button of "recording desktop" to start recording and demonstrate with explain. It should coordinate with marking tools or other multimedia software or materials to make teaching process vivid and interesting. Thirdly, do essential process and beautify to teaching video after completing recording.

3). Use portable video tools to shoot

a) Tools and software: phone with video camera, a dozen of white paper, different colors of pens and teaching plan for related topics. b) Making method: use portable camera to recording teaching process with papers and pencils' calculation and handwriting .

c) Process description: firstly, aiming at microlecture topics, do detailed teachings design to form teaching plan. Secondly, use pen to show teaching process on white papers. Instructors can draw, write and mark. With help of others, use mobile phones to recording teaching process. As far as possible to ensure that voice is clear, picture is stable, calculation has strong logic, and answer or explaining process is easy to understand. Thirdly, do essential process and beautify to teaching video after completing recording.

\section{CONCLUSION}

An Excellent microlecture should meet these requirements: firstly, be creative (set suspense, scene and so on) from original materials. Secondly, good topic is suitable for multimedia expression that is not only typical, key and difficult problem in teaching, but also not well resolved or not good problem in traditional teaching. Thirdly, microlecture is not classroom recording and classroom moving. Its contents should be characterized by inspiring, interesting and fascinating, and should have teaching process design, courseware design and teaching reflecting design. Fourth, the theme is clear and the contents are concise that can effectively solve practical problems of teaching and promote improvement of students' thinking ability. Fifth, recording picture is clear, voice is loud and distinct, and image is beautiful and exquisite such as titles, subtitles, flash display and other effects.

\section{REFERENCES}

[1] Home of microlecture. See design and making of microlecture from national award microlecture works. http://blog.sina.com.cn/s,2013.10.14

[2] Tool and tutorial for professional microlecture making. http://www.wkzj.net. 2015.1

[3] Baidu library. Training courses for making microlecture. http://wenku.baidu.com/view/, 2014.12.

[4] Baidu library. Illustrated books for using Camtasia Studio software. http://baike.baidu.com, 2015.2.

[5] G Shangfu. University computer foundation[M]. Xi'an electronic and science university press, 2012.9.

[6] G Xiaolin. Basic training for computer application [M]. Northwestern university press, 2010.9

Authors introduction:

Liang Chang (1964-), male, Xi'an Shaanxi, senior engineer, mainly engaged in teaching and research work of computer network and information technology.

Shangfu Gong(1954-), male, Xi'an Shaanxi, professor in Xi an University of Science and Technology, the main research direction is intelligent monitoring and control system, senior member of Chinese computer institute: 10848S. 